\title{
From promise to practice: pairing non-invasive sampling with genomics in conservation
}

Michael Russello, Matthew D Waterhouse, Paul D Etter, Eric A Johnson

Conservation genomics has become an increasingly popular term, yet it remains unclear whether the non-invasive sampling that is essential for many conservation-related studies is compatible with the minimum requirements for harnessing next-generation sequencing technologies. Here, we evaluated the feasibility of using genotyping-by-sequencing of noninvasively collected hair samples to simultaneously identify and genotype single nucleotide polymorphisms (SNPs) in a climate change-sensitive mammal, the American pika (Ochotona princeps). We identified and genotyped 3,803 high-confidence SNPs across eight sites distributed along two elevational transects using starting DNA amounts as low as 1 nanogram. Fifty-five outlier loci were detected as candidate gene regions under divergent selection, constituting potential targets for future validation. Genome-wide estimates of gene diversity significantly and positively correlated with elevation across both transects, with all low elevation sites exhibiting significant heterozygote deficit likely due to inbreeding. More broadly, our results highlight a range of issues that must be considered when pairing genomic data collection with non-invasive sampling, particularly related to field sampling protocols for minimizing exogenous DNA, data collection strategies and quality control steps for enhancing target organism yield, and analytical approaches for maximizing cost-effectiveness and information content of recovered genomic data. 
2 Title: From promise to practice: pairing non-invasive sampling with genomics in conservation 3

4 Michael A. Russello ${ }^{*}$, Matthew D. Waterhouse ${ }^{1}$, Paul D. Etter ${ }^{2}$ and Eric A. Johnson ${ }^{2}$

5

$6 \quad{ }^{1}$ Department of Biology, University of British Columbia, Okanagan Campus, 3427 University

7 Way, Kelowna, BC V1V 1V7, Canada

$8 \quad{ }^{2}$ SNPsaurus, Eugene, OR, USA

9

10

11 *Correspondence to: Michael Russello (michael.russello@ubc.ca); 250-807-8762

12

13 Running head: Pairing non-invasive sampling with genomics

14

15

16

17

18

19

20

21

22 


\section{Abstract}

24 Conservation genomics has become an increasingly popular term, yet it remains unclear whether

25 the non-invasive sampling that is essential for many conservation-related studies is compatible

26 with the minimum requirements for harnessing next-generation sequencing technologies. Here,

27 we evaluated the feasibility of using genotyping-by-sequencing of non-invasively collected hair

28 samples to simultaneously identify and genotype single nucleotide polymorphisms (SNPs) in a

29 climate change-sensitive mammal, the American pika (Ochotona princeps). We identified and

30 genotyped 3,803 high-confidence SNPs across eight sites distributed along two elevational

31 transects using starting DNA amounts as low as 1 nanogram. Fifty-five outlier loci were detected

32 as candidate gene regions under divergent selection, constituting potential targets for future

33 validation. Genome-wide estimates of gene diversity significantly and positively correlated with

34 elevation across both transects, with all low elevation sites exhibiting significant heterozygote

35 deficit likely due to inbreeding. More broadly, our results highlight a range of issues that must be

36 considered when pairing genomic data collection with non-invasive sampling, particularly

37 related to field sampling protocols for minimizing exogenous DNA, data collection strategies

38 and quality control steps for enhancing target organism yield, and analytical approaches for

39 maximizing cost-effectiveness and information content of recovered genomic data. 


\section{Introduction}

There has been much discussion on the transition of conservation genetics to conservation genomics (Helyar et al. 2011; McMahon et al. 2014). Genomic analysis provides the advantage of assessing natural selection and adaptive genetic variation (Schoville et al. 2012), accurately estimating levels of genome wide diversity (Vali et al. 2008), and providing novel information for delineating conservation units (Funk et al. 2012) and informing management strategies (Hoffmann et al. 2015). Yet, it remains unclear the degree to which the conservation community as a whole has embraced genomics as a useful tool, suggesting significant gaps in methodology and analysis that must be overcome before the technology is ready for real world applications (Shafer et al. 2015). One methodological aspect that has yet to be formally considered is the sample source of DNA; many population genetic studies of elusive or endangered species must rely on non-invasively collected samples. There is an expansive literature on the use of DNA from hair, feces, feathers and other non-invasively sampled materials for investigating the ecology, behavior, and population history of wildlife species (reviewed in Beja-Pereira et al. 2009; Waits \& Paetkau 2005). These studies have largely been based on single locus mitochondrial DNA (mtDNA) sequencing or multi-locus nuclear genotyping of hyper-variable loci, such as microsatellites (Taberlet et al. 1999; Waits \& Paetkau 2005). Modern genotypingby-sequencing approaches, such as those that rely on restriction-site associated DNA (RAD) tags, typically call for 1 microgram of high quality DNA for library construction (Baird et al. 2008; Etter et al. 2011). However, even highly refined DNA extraction protocols from noninvasively collected starting materials typically yield low concentrations of DNA, which may also contain PCR inhibitors (Beja-Pereira et al. 2009; Roon et al. 2003; Smith \& Wang 2014; Taberlet et al. 1999; Waits \& Paetkau 2005). To date, it remains unclear whether the non- 
invasive sampling that is essential for many conservation-related studies is compatible with the minimum requirements for harnessing the next generation sequencing (NGS) technologies necessary for expanding conservation genetics in the genomics era.

The American pika, Ochotona princeps, is an example of an elusive species that has benefited from the pairing of non-invasive sampling with genetic data collection. A small lagomorph, the American pika is discontinuously distributed in mountainous areas throughout western North America from central British Columbia and Alberta, Canada, south to the Sierra Nevada in California and east to New Mexico, USA. Pikas are restricted to talus slopes in proximity to meadows that provide their food (Smith \& Weston 1990). Exhibiting highly nonrandom distributions across mountaintop habitats, the average elevation of Great Basin $O$. princeps populations is currently $\sim 783 \mathrm{~m}$ higher than during the late Wisconsinian (Grayson 2005). In general, lower elevational limits are constrained by an inability to tolerate high temperatures, while high altitude distribution is possible through adaptation to hypoxic environments (Beever \& Smith 2011). The fragmented nature of their habitats has propelled $O$. princeps as a focal mammalian species for studies of metapopulation dynamics, island biogeography, source-sink dynamics (Beever et al. 2013; Peacock \& Smith 1997a), and extinction risk in the face of climate change (Beever et al. 2010; Hafner 1993; Smith 1974; Stewart et al. 2015).

Recent genetic studies of American pika have relied on samples obtained non-invasively using hair snares, which have greatly enhanced sample sizes while minimizing sampling effort (Henry \& Russello 2011). These studies revealed restricted dispersal capacity (Henry et al. 2012) and preliminary evidence for adaptive population divergence of American pika along elevation gradients at their northern range margin (Henry \& Russello 2013). These latter 
91 findings were based on amplified fragment length polymorphism (AFLP)-based genomic scans.

92 In addition to other undesirable properties, AFLPs are anonymous, dominant markers, which

93 precluded the identification of genes responsible for the observed adaptive divergence. Single

94 nucleotide polymorphisms (SNPs), with their broad genomic coverage and better-understood

95 mutation models, would overcome many of these limitations if they can be effectively genotyped

96 within the constraints imposed by this system and others involving elusive and endangered

97 species.

98 In the current study, we used nextRAD (Nextera-tagmented, reductively-amplified DNA)

99 genotyping to collect SNP data from American pikas sampled along parallel elevational

100 gradients to: 1) evaluate the feasibility of using DNA from non-invasively collected hair samples

101 to simultaneously identify and genotype SNPs in an elusive species; and 2) provide preliminary

102 insights into patterns of neutral and adaptive population divergence within this system.

103

104 Materials and Methods

105 Sample collection

106 This study was conducted in the North Cascades National Park, Washington, USA (Figure 1).

107 Sites within this national park present the opportunity to sample American pika along steep

108 elevational transects where climates change rapidly over short linear distances, while controlling

109 for other environmental and historical factors. Additionally, while pika are currently abundant in

110 the park, this area has been disproportionally affected by climate change (Karl et al. 2009). Pika

111 populations were sampled along two elevational transects [Pyramid Peak (PP) and Thornton

112 Lakes (TL)] between July and August 2013. Sites within transects ranged from $450 \mathrm{~m}$ to $1700 \mathrm{~m}$, 
113 representing an approximate $6^{\circ} \mathrm{C}$ gradient in mean annual temperature (Briggs et al. 1997) over

114 less than $6.5 \mathrm{~km}$ distance (Figure 1).

115 Non-invasive snares were used to obtain hair samples from 12 individuals at four sites

116 along each of the two transects $(n=96)$ following Henry and Russello (2011). To minimize

117 resampling the same animal, snares were set a minimum of $15 \mathrm{~m}$ apart and only one sample from

118 each snare was used. Subsequent genetic data were used to test the assumption that each sample

119 possessed a unique genotype (see below). All samples were collected under United States

120 Department of Interior National Park Service permit \# NOCA-2014-SCI-0022 and in accordance

121 with animal care protocol (A11-0371) as approved by the University of British Columbia's

122 Animal Care \& Biosafety Committee.

123

124 DNA isolation, genomic data collection and SNP discovery

125 Total genomic DNA was extracted using the DNA IQ Tissue and Hair Extraction Kit (Promega,

126 Madison, WI, USA) following the manufacturer's protocol. Each sample contained 60 hair

127 follicles with the majority of the hair shaft removed under a dissecting microscope to reduce

128 protein and other contamination. All DNA extractions were conducted in a separate laboratory

129 free of concentrated PCR products. Negative controls were included in each extraction to

130 monitor contamination. DNA quantifications were conducted using real-time PCR fluorescence

131 measurements of double stranded DNA (Blotta et al. 2005) and using the Quant-it kit (Life

132 Technologies, Foster City, CA).

133 Genomic DNA was converted into nextRAD genotyping-by-sequencing libraries

134 (SNPsaurus, LLC). The nextRAD method uses selective PCR primers to amplify genomic loci

135 consistently between samples. Genomic DNA (10 ng or less depending upon extraction yield) 
136 was first fragmented with Nextera reagent (Illumina, Inc), which also ligates short adapter

137 sequences to the ends of the fragments. Fragmented DNA was then amplified, with one of the

138 primers matching the adapter and extending 9 arbitrary nucleotides into the genomic DNA with

139 the selective sequence. Thus, only fragments starting with a sequence that can be hybridized by

140 the selective sequence of the primer will be efficiently amplified. The resulting fragments are

141 fixed at the selective end, and have random lengths depending on the initial Nextera

142 fragmentation. Because of this, amplified DNA from a particular locus is present at many

143 different sizes and careful size selection of the library is not needed. For this project, an arbitrary

144 9-mer was chosen from those previously validated in smaller genomes, which did not appear to

145 target repeat-masked regions in the publically available American pika genomic scaffolds

146 (Ensembl, release 74, Ochotona_princeps.74.dna_sm.toplevel.fa) and that would approximate the

147 results of standard RAD sequencing projects using Sbfl (Baird et al. 2008).

148 Since these samples were collected non-invasively, it was important to assess the

149 proportion of sequence reads in each sample that originated from the target organism relative to

150 other environmental sources prior to conducting genotyping analysis. This was done using a

151 custom script (SNPsaurus, LLC) that randomly sampled 1,000 high-quality reads from each

152 sample and aligned those to the publically available American pika genomic scaffolds as well as

153 subjected them to a BLASTN (Altschul et al. 1997) search of all sequences in the NCBI non-

154 redundant database. Only samples that had greater than $50 \%$ sequencing reads that mapped to

155 Ochotona princeps were retained for genotyping analysis.

156 The genotyping analysis used custom scripts (SNPsaurus, LLC) that created a reference

157 from abundant reads present between 500 and 2000 times across the combined set of samples,

158 mapping all of the reads to the reference allowing two mismatches. The identified variants were 
159 then filtered by removing loci that had more than the expected maximum of two alleles and those

160 that were present in less than $10 \%$ of all samples.

161 Following assembly, mapping and variant detection, the data were further filtered to

162 maximize data quality. We retained only those loci that were genotyped in $\geq 50 \%$ of individuals

163 from each transect, had a minor allele frequency $\geq 0.05$, and a minimum coverage of $6 \mathrm{X}$ for

164 homozygotes (affording 95\% confidence in the genotype) while heterozygotes were required to

165 have a minimum of $2 \mathrm{X}$ coverage per allele for each individual. These values were chosen to

166 minimize null alleles and sequencing errors from biasing homozygote and heterozygote genotype

167 calls, respectively. We then removed loci that displayed significant deviation from Hardy-

168 Weinberg equilibrium (HWE) in more than two sites per transect as assessed using the method of

169 Guo and Thompson (1992) as implemented in GENEPOP 4.3 (Raymond \& Rousset 1995; Rousset

170 2008).

171 To ensure that only non-redundant samples were included in subsequent analyses, we

172 conducted genotype matching across a random subset of 100 loci. We conducted the match

173 analysis and calculated the multi-locus probability of identity (Waits et al. 2001) for the 100

174 randomly chosen loci using GenAlEx (Peakall \& Smouse 2006). Only samples with unique

175 genotypes were retained.

176

177 Outlier locus detection and annotation

178 Polymorphic loci were screened for statistical outliers using the Bayesian simulation method of

179 Beaumont and Balding (2004) as implemented in BAYESCAN 2.1 (Foll \& Gaggiotti 2008). This

180 analysis was run independently for each transect, with all samples coded by site (PP1-PP4, TL1-

181 TL4). We used a prior odds value of 10, with 100,000 iterations and a burn-in of 50,000 
182 iterations. We identified loci that were significant outliers at a q-value of 0.20 . A q-value is a

183 false discovery rate (FDR) analogue of the p-value, with the former only defined in the context

184 of multiple testing, whereas the latter is defined on a single test. Consequently, a $20 \%$ threshold

185 for q-values is much more stringent than a $20 \%$ threshold for p-values in classical statistics. To

186 test for non-random association of genotypes, linkage disequilibrium was assessed between all

187 pairs of outlier loci in each population using the exact test of Guo and Thompson (1992) and

18810,000 dememorization steps, 100 batches, and 10,000 iterations per batch as implemented in

189 GENEPOP 4.3 (Raymond \& Rousset 1995; Rousset 2008). In addition, each haplotype from all

190 nextRAD-tags that contained outlier loci were subject to a BLASTN (Altschul et al. 1997) search

191 of all sequences in the NCBI non-redundant database (word size $=11$; mismatch scores $=2,-3$;

192 maximum e-value $=10-15$ ). To reduce annotations to repetitive sequences in the database, we

193 required either a unique BLASTN hit or a top hit with an $e$-value that was at least an order of

194 magnitude lower than the next closest hit.

195

196 Population genetic analyses

197 We segregated loci into two datasets including: 1) all loci identified as an outlier ("outlier

198 dataset"); and 2) all loci not identified as an outlier ("neutral dataset"). The neutral dataset was

199 used to conduct standard population genetic analyses for quantifying the extent and distribution

200 of variation within and among sites. Within sites, proportion of polymorphic loci, observed $\left(H_{o}\right)$

201 and expected $\left(H_{e}\right)$ heterozygosity, and gene diversity $\left(N_{g}\right)$ were calculated using ARLEQUIN 3.5

202 (Excoffier \& Lischer 2010). Global tests for heterozygote deficit were conducted using Fisher's

203 method and 10,000 dememorization steps, 100 batches, and 10,000 iterations per batch as

204 implemented in GENEPOP 4.3 (Raymond \& Rousset 1995; Rousset 2008). The inbreeding 
205 coefficient, $F_{i s}$, was calculated for each site as implemented in GENETIX (Belkhir et al. 2004),

206 with significance assessed using 1000 permutations. To evaluate whether site-level genetic

207 diversity was correlated with elevation and sample size, we conducted linear regression analyses

208 implemented in R v. 3.1 (R Development Core Team 2011).

209 Levels of genetic differentiation among groups were estimated by pairwise comparisons

210 of $\theta$ (Weir \& Cockerham 1984), as calculated in GENETIX (Belkhir et al. 2004), and evaluated

211 using 1,000 permutations. The hierarchical organization of genetic variation within and among

212 transects was calculated using an analysis of molecular variance (AMOVA) as implemented in

213 ARLEQUIN 3.5 (Excoffier \& Lischer 2010), with significance assessed using 1,000 permutations.

214 In addition, the model-based clustering method implemented in STRUCTURE 2.3.4 (Pritchard et

215 al. 2000) was used to infer the number of discrete genetic units across both transects. Run length

216 was set to $100,000 \mathrm{MCMC}$ replicates after a burn-in period of 100,000 using correlated allele

217 frequencies under a straight admixture model. We varied the number of clusters $(K)$ from 1 to 10 ,

218 with 10 replicates for each value of $K$. The most likely number of clusters was determined by

219 plotting the $\log$ probability of the data $(\ln \operatorname{Pr}(X \mid K)$ (Pritchard et al, 2000) across the range of $K$

220 values tested and selecting the $K$ where the value of $\ln \operatorname{Pr}(X \mid K)$ plateaued as suggested in the

221 StRUCtURE manual. We also employed the $\Delta K$ method (Evanno et al. 2005) as calculated in

222 Structure HARVESTER (Earl 2011). Results for the identified optimal values of $K$ were

223 summarized using CLUMPP (Jakobsson \& Rosenberg 2007) and plotted using DISTRUCT

224 (Rosenberg 2004). In order to test for unrecognized substructure in the broader STRUCTURE

225 analysis, we repeated the above analysis for each transect separately using neutral and outlier 226 loci. 


\section{Results}

229 Data quality

230 The mean starting DNA concentration recovered from the non-invasively collected hair samples

231 was $0.55 \mathrm{ng} / \mu 1$ with as little as $1 \mathrm{ng}$ total for some samples. The mean number of sequencing

232 reads per sample was $1,863,634$. Ten samples yielded less than 100,000 sequencing reads, likely

233 due to the degraded quality and very low quantity of starting DNA. Nineteen additional samples

234 had less than $50 \%$ of their sequencing reads mapping to O. princeps. Sixteen of these samples

235 had high proportions of sequence reads matching with two small mammals that likely co-occur

236 in the sampling area [Mus musculus $(\mathrm{n}=13)$ and Spermophilus $(\mathrm{n}=3)$ ], with others matching

237 Homo sapiens $(\mathrm{n}=2)$ and Zea mays $(\mathrm{n}=1)$. The above samples $(\mathrm{n}=29)$ with low overall sequence

238 reads or a low proportion mapping to $O$. princeps (or both) were removed, leaving 67 samples

239 from eight sites across two elevational transects that were subject to all downstream analyses

240 (Figure 1; Table 2).

241 We identified 9,825 SNPs that met the minimum parameters for recovering genotypes.

242 To minimize linkage, we retained the highest coverage SNP from each contig, resulting in 3,830

243 SNPs. Twenty-seven SNPs deviated from HWE in two or more sites per transect and were

244 removed from the dataset. Consequently, all downstream analyses were based on genotypic data

245 at 3,803 SNPs. All 67 of the retained samples possessed unique genotypes at a random subset of

246100 loci (average probability of identity within each sampling site $=1.1 \times 10^{-23}$ ), suggestive of

247 unique individuals.

Outlier loci detection and annotation 
250 Outlier detection identified 37 loci along the TL transect and 18 loci along the PP transect, none

251 of which were shared. There was no evidence of significant deviation from linkage equilibrium

252 for any pairwise comparison of outlier loci across populations. Fourteen outlier loci

253 unambiguously matched sequences from the NCBI nr database, five of which annotated to genes

254 of known functions (Table 1). Locus 57863_76 identified from the PP transect mapped to the

255 receptor tyrosine kinase-like orphan receptor 2 (ROR2) gene that is part of a conserved family

256 that function in developmental processes including skeletal and neuronal development, cell

257 movement and cell polarity (Green et al. 2008). Likewise, locus 108547_114 identified from the

258 TL transect annotated to another gene encoding a cell surface tyrosine kinase receptor (beta-type

259 platelet-derived growth factor receptor), but for members of the platelet-derived growth factor

260 family (Shim et al. 2010). Locus (28594_45) was similar to the laminin alpha 3 gene in humans

261 that codes for a protein that is essential for formation and function of the basement membrane,

262 with additional functions in regulating cell migration and mechanical signal transduction (Hamill

263 et al. 2010). Lastly, locus 23486_75 was annotated to the hephaestin-like 1 (HEPHL1) gene that

264 may function as a ferroxidase and may be involved in copper transport and homeostasis, while

265 locus 33398_46 mapped to thioredoxin-related transmembrane protein 4 (TMX4) that may act as

266 a reductase in the calnexin folding complex (Sugiura et al. 2010).

268 Population genetic analyses

269 The proportion of polymorphic loci varied across the sampling sites, with the lower elevation 270 sites (PP1, PP2, TL1) exhibiting substantially lower numbers $(P=0.661-0.777)$ than found at the

271 mid- and high-elevation sites $(P=0.837-0.947)$ for both transects (Table 2). Similar trends were

272 seen for gene diversity along both transects where the low and mid- elevation sites recorded the 
273 lowest values relative to higher elevation sites (Table 2). Indeed, both measures of site-level

274 genetic variation were significantly correlated with elevation $\left(P: r^{2}=0.557, p=0.034 ; N_{g}: r^{2}=0.738\right.$

$275 p=0.006$; Figure 2). Although $P$ significantly correlated with sample size $\left(r^{2}=0.635, p=0.018\right)$,

276 this was not the case for gene diversity $\left(r^{2}=0.0813, p=0.493\right)$ or elevation $\left(r^{2}=0.184, p=0.289\right)$.

277 This general trend of increasing variation with elevation seemed to hold for observed

278 heterozygosity along the PP transect, but were stable across TL sites $\left(H_{o}: 0.336-0.368\right.$; Table 2$)$.

279 Yet, all low (PP1, TL1) and mid-low (PP2, TL2) sites exhibited significant, genome-wide

280 evidence of heterozygote deficit. Interestingly, significant inbreeding was also detected at the

281 low and mid-low elevation sites along PP, with no such evidence at the higher elevation sites

282 (PP3, PP4; Table 2). All sites along the TL transect exhibited evidence of inbreeding (Table 2).

283 The AMOVA revealed that a significant amount of variation $(\mathrm{p}<0.0001)$ was exhibited

284 both among transect $(4.14 \%$, d.f. $=1)$ and among sites within transect $(2.01 \%$, d.f. $=6)$, with the 285 remaining found within populations $(93.05 \%$, d.f. $=126)$. These patterns were congruent with 286 those from pairwise $\theta$ estimates, with the highest values generally displayed by among transect 287 comparisons, but where all comparisons were significant (Table 3).

288 The Bayesian clustering analyses based on 3,748 neutral loci revealed strong evidence for 289 two clusters within the dataset $\left(\Delta K_{2}=249.0\right)$, corresponding to the two transects (Figure 1).

290 When analyzing the PP transect separately, additional substructure $(K=2$; Figure 3$)$ was found 291 using neutral $\left(\Delta K_{2}=33.1\right)$ and outlier $\left(\Delta K_{2}=123.1\right)$ loci. In both cases, the low elevation site 292 (PP1) represents a largely distinct cluster relative to all other sites. Similarly, substructure was 293 found along the TL transect when using outlier loci, with strong evidence for two $\left(\Delta K_{2}=473.3\right)$ 294 and three $\left(\Delta K_{3}=314.6\right)$ clusters. In the $K=2$ plot, TL2 represented a distinct cluster, while in the $295 K=3$ plot, the lower elevation sites (TL1, TL2) were each separate clusters relative to the high 
296 elevation sites. Although the Evanno et al. (2005) method would favor $K=2$, the method

297 described by Pritchard et al (2000) for inferring the optimal number of clusters would suggest $K$

$298=3$ given that $\ln \operatorname{Pr}(X \mid K)$ clearly plateaus at this value (Table S1). No substructure was found

299 along the TL transect based on neutral loci.

300

301 Discussion

302 Conservation genomics has become an increasingly popular term in the literature, yet practical

303 examples are limited (Shafer et al. 2015), including explicit consideration of the efficacy of

304 genomic data collection from non-invasively collected starting materials. Here, we demonstrated

305 the ability to identify 3,803 high confidence SNPs and recover genotypic data from low quantity

306 DNA originating from non-invasively collected American pika hair samples. These data allowed

307 us to detect outlier loci across elevational transects, identifying several candidate gene regions

308 that exhibit putative signatures of divergent selection and that can be investigated in future

309 studies for formulating mechanistic hypotheses. Moreover, the broad-scale genomic coverage

310 enabled precise estimation of population-level parameters, including standard diversity indices,

311 inbreeding, and structure within and among sampled transects.

312 We found genetic variation to be significantly correlated with elevation (Figure 2), with

313 sites at the lower fringe of American pika distribution in North Cascades National Park

314 exhibiting substantially lower levels of gene diversity. No such associations were found in a

315 previous microsatellite-based study conducted across elevationally distributed sites in British

316 Columbia, Canada (Henry et al. 2012). The detection of significant genome-wide evidence of

317 heterozygote deficit at low elevation sites in both transects further suggests inbreeding may be

318 leading to the observed patterns (Table 2), a particular concern for PP1, TL1 and TL2 given their 
319 apparent distinctiveness from higher elevation sites (Figure 3). Due to their specific habitat

320 requirements, patchy distribution, and life history, American pikas were long thought to

321 regularly interbreed with close relatives based on observational studies (Smith 1993; Smith \&

322 Ivins 1983). Yet, molecular marker based studies have altered our understanding of American

323 pika breeding behavior, revealing evidence for mate choice based on intermediate relatedness in

324 one case (Peacock \& Smith 1997b), while another found no evidence for inbreeding across

325 elevationally distributed sites (Henry et al. 2012). This latter study conducted in Tweedsmuir

326 South Provincial Park, British Columbia, Canada also found evidence for broad-scale and fine-

327 scale population structure, detecting restricted gene flow among transects as well as among sites

328 within transect and potentially driven by climatic factors (Henry et al. 2012). Although

329 conducted at a different scale, Castillo et al. (2014) found a high degree of connectivity among

330 geographically proximate sites in Crater Lake National Park, Oregon, USA, but restricted gene

331 flow at a broader scale likely driven by topographic complexity and water. Here, we detected

332 similar coarse-level patterns, detecting strong population genetic structure across transects but

333 some evidence of connectivity between sites within transects in North Cascades National Park. It

334 is worth noting that the three studies spanned the distribution of the Cascades lineage of

335 American pika (Galbreath et al. 2009), conducted in the north (Henry et al. 2012), south (Castillo

336 et al. 2014) and central (this study) portions of the range. Given that pikas are considered by

337 some to be sentinels of climate change (Hafner 1993; Smith 1974), further investigation is

338 warranted to infer underlying mechanisms associated with dispersal ability in pikas that may be

339 further enhanced by comparative analyses of elevationally- and latitudinally-distributed sites.

340 More broadly, our results highlight a range of issues that must be considered when

341 pairing genomic data collection with non-invasive sampling. First, sampling protocols must 
342 endeavor to minimize non-target DNA during the collection process. In our case, the use of tape-

343 based, non-invasive hair snares allowed us to collect genomic data from 67 individuals of

344 American pika, but also yielded 19 samples that were almost entirely composed of DNA

345 sequence reads from non-target organisms, primarily other small mammals that were likely using

346 the same talus habitat. Precautions to avoid such contamination will vary according to the

347 methods in which samples are obtained, but are of critical importance given the non-targeted

348 nature of NGS approaches. Depending upon study questions, the use of exon-capture or other

349 approaches for preferentially targeting the DNA of study organisms within a mixed sample may

350 help to minimize contamination and maximize cost-effectiveness of downstream sequence data

351 (Avila-Arcos et al. 2011; Carpenter et al. 2013; Good 2011). Exon-capture, in particular, has

352 been effectively applied to historical DNA collected from museum specimens (Bi et al. 2013),

353 which typically yield DNA of lower quantity and quality similar to non-invasively collected

354 starting materials. Yet, these approaches are substantially more costly and, in the case of exon-

355 capture, limited to expressed regions of the genome. However, for some non-invasively collected

356 source of DNA such as feces, the use of capture approaches may be obligatory (Perry et al.

357 2010).

358 Additionally, rigorous assessments of resulting DNA sequence data must be undertaken

359 to ensure quality control. In the current study, we used a genotyping-by-sequencing approach for

360 reduced representation genomic data collection. We had the advantage of publicly available

361 American pika genomic scaffolds that allowed us to initially filter our data based on SNPs

362 assembling to these references. At present, such resources may not be available for many

363 organisms of conservation interest. In such cases, we recommend using the closest available

364 genome to inform reference assembly of identified SNPs (in our case, this would have been the 
365 European rabbit; Lindblad-Toh et al. 2011). If no suitable reference genome is available,

366 investigators may want to consider capture approaches for genomic data collection (as discussed

367 above).

368 Analytical frameworks must also be carefully considered in relation to recovered

369 sequence coverage depth in studies using non-invasively collected samples. In our case, we used

370 explicit parameters related to coverage and amounts of allowable missing data to confidently

371 reconstruct genotypes from our sampled individuals. While there is no clear standard in the

372 literature, choice of such parameters is a balance between maximizing the number of loci and

373 minimizing null alleles when reconstructing genotypes. Yet, reconstructed genotypes may not be

374 necessary for all study questions, especially those primarily focused on estimating population-

375 level parameters rather than individual-based measures (e.g. admixture coefficients, individual

376 identification, parentage probabilities; but see Buerkle \& Gompert 2013). In such cases, low

377 density genomic scans based on more individuals or sites in the genome may provide highly

378 accurate and precise population parameter estimates, even at as low as $1 \mathrm{X}$ coverage (Buerkle \&

379 Gompert 2013; Fumagalli 2013). Analytical pipelines continue to be developed that implement

380 population genetic analysis methods that account for the statistical uncertainty of NGS data

381 (Fumagalli et al. 2014), with empirical examples now found in the literature (Cahill et al. 2013).

382 Overall, NGS data and population genomic analyses hold great promise for informing

383 conservation-related studies, substantially increasing the number of markers to allow for more

384 accurate and precise estimates of population structure and demographic parameters (Primmer

385 2009), as well as the ability to detect adaptive genetic variation for informing conservation unit

386 delimitation (Funk et al. 2012) and decision frameworks aimed at reducing the long-term impacts

387 of climate change on biodiversity (Hoffmann et al. 2015). Here, we have shown that with 


\section{PeerJ Reviewing Manuscript}

388

389

390

391

392

393

394

395

396

397

398

399

400

401

402

403

404

405

406

407

408

409

410

411

412

413

414

415

416

417

418

419

420

careful consideration, genomic data collection is compatible with the non-invasive sampling required in practice for many conservation-related studies.

\section{Acknowledgments}

We thank Regina Rochefort, Roger Christophersen, Liesl Erb, Kelsey Robson, Shane

Schoolman, and Aidan Beers for assistance with site selection and sampling. Evelyn Jensen and

Andrew Veale provided feedback on the manuscript. Holly Buhler helped prepare the map

figure. A special thanks to the Department of Organismic and Evolutionary Biology at Harvard

University for hosting MR during his sabbatical visit, during which some of the initial

development of this work occurred.

\section{References}

Altschul SF, Madden TL, Schaffer AA, Zhang JH, Zhang Z, Miller W, and Lipman DJ. 1997. Gapped BLAST and PSI-BLAST: a new generation of protein database search programs. Nucleic Acids Research 25:3389-3402.

Avila-Arcos MC, Cappellini E, Alberto Romero-Navarro J, Wales N, Victor Moreno-Mayar J, Rasmussen M, Fordyce SL, Montiel R, Vielle-Calzada J-P, Willerslev E, and Gilbert MTP. 2011. Application and comparison of large-scale solution-based DNA captureenrichment methods on ancient DNA. Scientific Reports 1.

Baird NA, Etter PD, Atwood TS, Currey MC, Shiver AL, Lewis ZA, Selker EU, Cresko WA, and Johnson EA. 2008. Rapid SNP discovery and genetic mapping using sequenced RAD markers. PLoS ONE 3:e3376.

Beaumont MA, and Balding DJ. 2004. Identifying adaptive genetic divergence among populations from genome scans. Molecular Ecology 13:969-980.

Beever EA, Dobrowski SZ, Long J, Mynsberge AR, and Piekielek NB. 2013. Understanding relationships among abundance, extirpation, and climate at ecoregional scales. Ecology 94:1563-1571.

Beever EA, Ray C, Mote PW, and Wilkening JL. 2010. Testing alternative models of climatemediated extirpations. Ecological Applications 20:164-178.

Beever EA, and Smith AT. 2011. Ochotona princeps. IUCN Red List of Threatened Species.

Beja-Pereira A, Oliveira R, Alves PC, Schwartz MK, and Luikart G. 2009. Advancing ecological understandings through technological transformations in noninvasive genetics. Molecular Ecology Resources 9:1279-1301. 
421

422

423

424

425

426

427

428

429

430

431

432

433

434

435

436

437

438

439

440

441

442

443

444

445

446

447

448

449

450

451

452

453

454

455

456

457

458

459

460

461

462

463

464

465

466

Belkhir K, Borsa P, Chikhi L, Raufaste N, and Bonhomme F. 2004. GENETIX 4.0.5.2., Windows TM software for population genetics. Laboratoire Génome, Populations, Interactions, CNRS UMR 5171. Montpellier, France: Université de Montpellier II.

Bi K, Linderoth T, Vanderpool D, Good JM, Nielsen R, and Moritz C. 2013. Unlocking the vault: next-generation museum population genomics. Molecular Ecology 22:6018-6032.

Blotta I, Prestinaci F, Mirante S, and Cantafora A. 2005. Quantitative assay of total dsDNA with PicoGreen reagent and real-time fluorescent detection. Annali dell'Istituto superiore di sanita 41:119-123.

Buerkle CA, and Gompert Z. 2013. Population genomics based on low coverage sequencing: how low should we go? Molecular Ecology 22:3028-3035.

Cahill JA, Green RE, Fulton TL, Stiller M, Jay F, Ovsyanikov N, Salamzade R, St John J, Stirling I, Slatkin M, and Shapiro B. 2013. Genomic evidence for island population conversion resolves conflicting theories of polar bear evolution. Plos Genetics 9.

Carpenter ML, Buenrostro JD, Valdiosera C, Schroeder H, Allentoft ME, Sikora M, Rasmussen M, Gravel S, Guillen S, Nekhrizov G, Leshtakov K, Dimitrova D, Theodossiev N, Pettener D, Luiselli D, Sandoval K, Moreno-Estrada A, Li Y, Wang J, Gilbert MTP, Willerslev E, Greenleaf WJ, and Bustamante CD. 2013. Pulling out the 1\%: WholeGenome Capture for the Targeted Enrichment of Ancient DNA Sequencing Libraries. American Journal of Human Genetics 93:852-864.

Castillo JA, Epps CW, Davis AR, and Cushman SA. 2014. Landscape effects on gene flow for a climate-sensitive montane species, the American pika. Molecular Ecology 23:843-856.

Earl DA. 2011. Structure harvester v0.6.5. Available at http://taylor0.biology.ucla.edu/struct_harvest/.

Etter PD, Bassham S, Hohenlohe PA, Johnson EA, and Cresko WA. 2011. SNP discovery and genotyping for evolutionary genetics using RAD sequencing. Methods in molecular biology (Clifton, NJ) 772:157-178.

Evanno G, Regnaut S, and Goudet J. 2005. Detecting the number of clusters of individuals using the software STRUCTURE: a simulation study. Molecular Ecology 14:2611-2620.

Excoffier L, and Lischer HEL. 2010. Arlequin suite ver 3.5: a new series of programs to perform population genetics analyses under Linux and Windows. Molecular Ecology Resources 10:564-567.

Foll M, and Gaggiotti O. 2008. A genome-scan method to identify selected loci appropriate for both dominant and codominant markers: a bayesian perspective. Genetics 180:977-993.

Fumagalli M. 2013. Assessing the effect of sequencing depth and sample size in population genetics inferences. PLOS ONE 8.

Fumagalli M, Vieira FG, Linderoth T, and Nielsen R. 2014. ngsTools: methods for population genetics analyses from next-generation sequencing data. Bioinformatics 30:1486-1487.

Funk CW, McKay JK, Hohenlohe PA, and Allendorf FW. 2012. Harnessing genomics for delineating conservation units. Trends in Ecology and Evolution 27:489-496.

Galbreath KE, Hafner DJ, and Zamudio KR. 2009. When Cold Is Better: Climate-Driven Elevation Shifts Yield Complex Patterns of Diversification and Demography in an Alpine Specialist (American Pika, Ochotona Princeps). Evolution 63:2848-2863.

Good JM. 2011. Reduced representation methods for subgenomic enrichment and nextgeneration sequencing. Methods in Molecular Biology 772:85-103.

Grayson DK. 2005. A brief history of Great Basin pikas. Journal of Biogeography 32:21032111. 
467

Green JL, Kuntz SG, and Sternberg PW. 2008. Ror receptor tyrosine kinases: orphans no more. Trends in Cell Biology 18:536-544.

Guo SW, and Thompson EA. 1992. Performing the exact test of Hardy-Weinberg proportion for multiple alleles. Biometrics 48:361-372.

Hafner DJ. 1993. North-American Pika (Ochotona-Princeps) as a Late Quaternary Biogeographic Indicator Species. Quaternary Research 39:373-380.

Hamill KJ, Paller AS, and Jones JCR. 2010. Adhesion and Migration, the Diverse Functions of the Laminin alpha 3 Subunit. Dermatologic Clinics 28:79-+.

Helyar SJ, Hemmer-Hansen J, Bekkevold D, Taylor MI, Ogden R, Limborg MT, Cariani A, Maes GE, Diopere E, Carvalho GR, and Nielsen EE. 2011. Application of SNPs for population genetics of nonmodel organisms: new opportunities and challenges. Molecular Ecology Resources 11:123-136.

Henry P, and Russello MA. 2011. Obtaining high-quality DNA from elusive small mammals using low-tech hair snares. European Journal of Wildlife Research 57:429-435.

Henry P, and Russello MA. 2013. Adaptive divergence along environmental gradients in a climate-change-sensitive mammal. Ecology and Evolution 3:3906-3917.

Henry P, Sim Z, and Russello MA. 2012. Genetic evidence for highly restricted dispersal along continuous altitudinal gradients in the climate-change sensitive American pika. PLoS ONE 7:e39077.

Hoffmann A, Griffin P, Dillon S, Catullo R, Rane R, Byrne M, Jordan R, Oakeshott J, Weeks A, Joseph L, Lockhart P, Borevitz J, and Sgrò C. 2015. A framework for incorporating evolutionary genomics into biodiversity conservation and management. Climate Change Responses 2:1 (24 pages).

Jakobsson M, and Rosenberg NA. 2007. CLUMPP: a cluster matching and permutation program for dealing with label switching and multimodality in analysis of population structure. Bioinformatics 23:1801-1806.

Karl TR, Melillo JM, Peterson TC, Anderson DM, Boesch DF, Burkett V, Carter LM, Cohen SJ, Grimm NB, Hatfield JL, Hayhoe K, Janetos A, Kaye JA, Lawrimore J, McCarthy J, McGuire AD, Miles E, Mills E, Overpeck JT, Patz J, Pulwarthy R, Santer B, Savonis MJ, Schwartz HG, Shea E, Stone J, Udall BH, Walsh J, Wehner MF, Wilbanks TJ, and Wuebbles D. 2009. Global Climate Change Impacts in the United States: A State of Knowledge Report from the U.S. Global Change Research Program. New York: Cambridge University Press.

Lindblad-Toh K, Garber M, Zuk O, Lin MF, Parker BJ, Washietl S, Kheradpour P, Ernst J, Jordan G, Mauceli E, Ward LD, Lowe CB, Holloway AK, Clamp M, Gnerre S, Alfoeldi J, Beal K, Chang J, Clawson H, Cuff J, Di Palma F, Fitzgerald S, Flicek P, Guttman M, Hubisz MJ, Jaffe DB, Jungreis I, Kent WJ, Kostka D, Lara M, Martins AL, Massingham T, Moltke I, Raney BJ, Rasmussen MD, Robinson J, Stark A, Vilella AJ, Wen J, Xie X, Zody MC, Worley KC, Kovar CL, Muzny DM, Gibbs RA, Warren WC, Mardis ER, Weinstock GM, Wilson RK, Birney E, Margulies EH, Herrero J, Green ED, Haussler D, Siepel A, Goldman N, Pollard KS, Pedersen JS, Lander ES, Kellis M, Broad I, Baylor Coll M, and Washington U. 2011. A high-resolution map of human evolutionary constraint using 29 mammals. Nature 478:476-482.

McMahon BJ, Teeling EC, and Hoglund J. 2014. How and why should we implement genomics into conservation? Evolutionary Applications 7:999-1007. 
512 Peacock MM, and Smith AT. 1997a. The effect of habitat fragmentation on dispersal patterns,

513

514

515

516

517

518

519

520

521

522

523

524

525

526

527

528

529

530

531

532

533

534

535

536

537

538

539

540

541

542

543

544

545

546

547

548

549

550

551

552

553

554

555

556 mating behavior, and genetic variation in a pika (Ochotona princeps) metapopulation. Oecologia 112:524-533.

Peacock MM, and Smith AT. 1997b. Nonrandom mating in pikas Ochotona princeps: evidence for inbreeding between individuals of intermediate relatedness. Molecular Ecology 6:801-811.

Peakall R, and Smouse PE. 2006. GENALEX 6: genetic analysis in Excel. Population genetic software for teaching and research. Molecular Ecology Notes 6:288-295.

Perry GH, Marioni JC, Melsted P, and Gilad Y. 2010. Genomic-scale capture and sequencing of endogenous DNA from feces. Molecular Ecology 19:5332-5344.

Primmer CR. 2009. From Conservation Genetics to Conservation Genomics. Year in Ecology and Conservation Biology 2009 1162:357-368.

Pritchard JK, Stephens M, and Donnelly P. 2000. Inference of population structure using multilocus genotype data. Genetics 155:945-959.

R Development Core Team. 2011. R: A language and environment for statistical computing. R Foundation for Statistical Computing, Vienna, Austria.

Raymond M, and Rousset F. 1995. GENEPOP (version-1.2) - population genetics software for exact tests and ecumenicism. Journal of Heredity 86:248-249.

Roon DA, Waits LP, and Kendall KC. 2003. A quantitative evaluation of two methods for preserving hair samples. Molecular Ecology Notes 3:163-166.

Rosenberg NA. 2004. DISTRUCT: a program for the graphical display of population structure. Molecular Ecology Notes 4:137-138.

Rousset F. 2008. GENEPOP ' 007: a complete re-implementation of the GENEPOP software for Windows and Linux. Molecular Ecology Resources 8:103-106.

Schoville SD, Bonin A, Francois O, Lobreaux S, Melodelima C, and Manel S. 2012. Adaptive genetic variation on the landscape: methods and cases. Annual Review of Ecology, Evolution, and Systematics 43:23-43.

Shafer ABA, Wolf JBW, Alves PC, Bergström L, Bruford MW, Brännström I, Colling G, Dalén L, Meester LD, Ekblom R, Fawcett KD, Fior S, Hajibabaei M, Hill JA, Hoezel AR, Höglund J, Jensen EL, Krause J, Kristensen TN, Krützen M, McKay JK, Norman AJ, Ogden R, Österling EM, Ouborg NJ, Piccolo J, Popović D, Primmer CR, Reed FA, Roumet M, Salmona J, Schenekar T, Schwartz MK, Segelbacher G, Senn H, Thaulow J, Valtonen M, Veale A, Vergeer P, Vijay N, Vilà C, Weissensteiner M, Wennerström L, Wheat CW, and Zieliński P. 2015. Genomics and the challenging translation into conservation practice. Trends in Ecology \& Evolution 30:78-87.

Shim AH-R, Liu H, Focia PJ, Chen X, Lin PC, and He X. 2010. Structures of a platelet-derived growth factor/propeptide complex and a platelet-derived growth factor/receptor complex. Proceedings of the National Academy of Sciences of the United States of America 107:11307-11312.

Smith AT. 1974. Distribution and Dispersal of Pikas - Influences of Behavior and Climate. Ecology 55:1368-1376.

Smith AT. 1993. The natural history of inbreeding and outbreeding in small mammals.

Smith AT, and Ivins BL. 1983. Colonization in a Pika Population - Dispersal Vs Philopatry. Behavioral Ecology and Sociobiology 13:37-47.

Smith AT, and Weston ML. 1990. Ochotona princeps. Mammalian Species 352:1-8. 
557

558

559

560

561

562

563

564

565

566

567

568

569

570

571

572

573

574

575

576

577

578

579

580

581

582

583

584

Smith O, and Wang J. 2014. When can noninvasive samples provide sufficient information in conservation genetics studies? Molecular Ecology Resources 14:1011-1023.

Stewart JAE, Perrine JD, Nichols LB, Thorne JH, Millar CI, Goehring KE, Massing CP, and Wright DH. 2015. Revisiting the past to foretell the future: summer temperature and habitat area predict pika extirpations in California. Journal of Biogeography 42:880-890.

Sugiura Y, Araki K, Iemura S-i, Natsume T, Hoseki J, and Nagata K. 2010. Novel Thioredoxinrelated Transmembrane Protein TMX4 Has Reductase Activity. Journal of Biological Chemistry 285:7135-7142.

Taberlet P, Waits LP, and Luikart G. 1999. Noninvasive genetic sampling: look before you leap. Trends in Ecology \& Evolution 14:323-327.

Vali U, Einarsson A, Waits L, and Ellegren H. 2008. To what extent do microsatellite markers reflect genome-wide genetic diversity in natural populations? Molecular Ecology 17:3808-3817.

Waits LP, Luikart G, and Taberlet P. 2001. Estimating the probability of identity among genotypes in natural populations: cautions and guidelines. Molecular Ecology 10:249256.

Waits LP, and Paetkau D. 2005. Noninvasive genetic sampling tools for wildlife biologists: A review of applications and recommendations for accurate data collection. Journal of Wildlife Management 69:1419-1433.

Weir BS, and Cockerham CC. 1984. Estimating F-statistics for the analysis of population structure. Evolution 38:1358-1370.

\section{Supporting Information Captions}

Table S1. Summarized STRUCTURE output including $\Delta K$ for the Thornton Lake elevational transect based on 37 outlier loci.

\section{Data Accessibility}

All SNP genotypic data are deposited in Dryad doi: \#\#\#\#. 


\section{Figure Captions}

587 Figure 1. Sites in North Cascades National Park, Washington, USA where America pika hair 588 samples were non-invasively collected. Topographic lines represent $100 \mathrm{~m}$ elevation. Inset

589 shows a STRUCTURE bar plot depicting the model-based clustering results for all sites within the 590 Pyramid Peak (PP) and Thornton Lake (TL) elevational transects based on 3,748 neutral single 591 nucleotide polymorphisms.

592

593 Figure 2. Elevational patterns of genetic diversity within American pika samples in the North

594 Cascade National Park. Solid line shows the correlation between proportions of polymorphic loci 595 ( $P$; circles $)$ with elevation $\left(r^{2}=0.557 p=0.034\right)$. Dashed line shows the correlation between gene 596 diversity $\left(N_{g}\right.$; squares $)$ with elevation $\left(r^{2}=0.738 p=0.006\right)$.

598 Figure 3. STRUCTURE bar plots depicting the model-based clustering results for Thornton Lake 599 (TL) and Pyramid Peak (PP) sites based on outlier loci (above) and neutral loci (below).

600 Analyses for the TL transect revealed evidence for both $K=2(\Delta K=473.3)$ and $K=3(\Delta K=$

601 314.6; plot shown) based on 37 outlier loci, and $K=1$ ( $K=2$ plot shown for display purposes)

602 based on 3748 neutral loci. Analyses for the PP transect revealed evidence for $K=2$ ( $\triangle K=$

603 123.1) based on 18 outlier loci, and $K=2(\Delta K=33.1)$ based on 3,748 neutral loci. 


\section{1}

Figure 1: Sites in North Cascades National Park, Washington, USA where America pika hair samples were non-invasively collected.

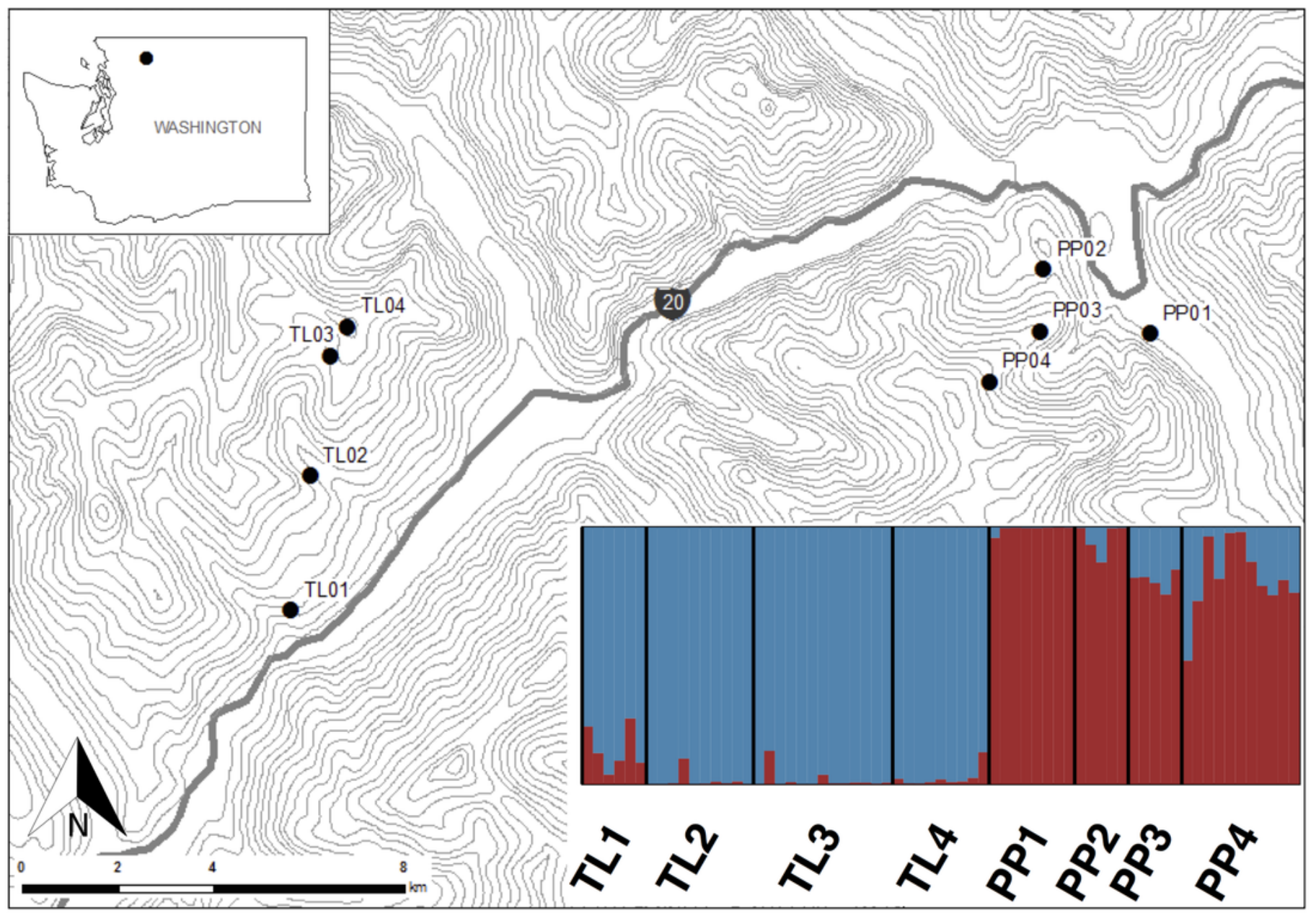


2

Figure 2: Elevational patterns of genetic diversity within American pika samples in the North Cascade National Park.

Solid line shows the correlation between proportions of polymorphic loci ( $P$; circles) with elevation $\left(r^{2}=0.557 p=0.034\right)$. Dashed line shows the correlation between gene diversity $\left(N_{g}\right.$; squares) with elevation $\left(r^{2}=0.738 p=0.006\right)$.

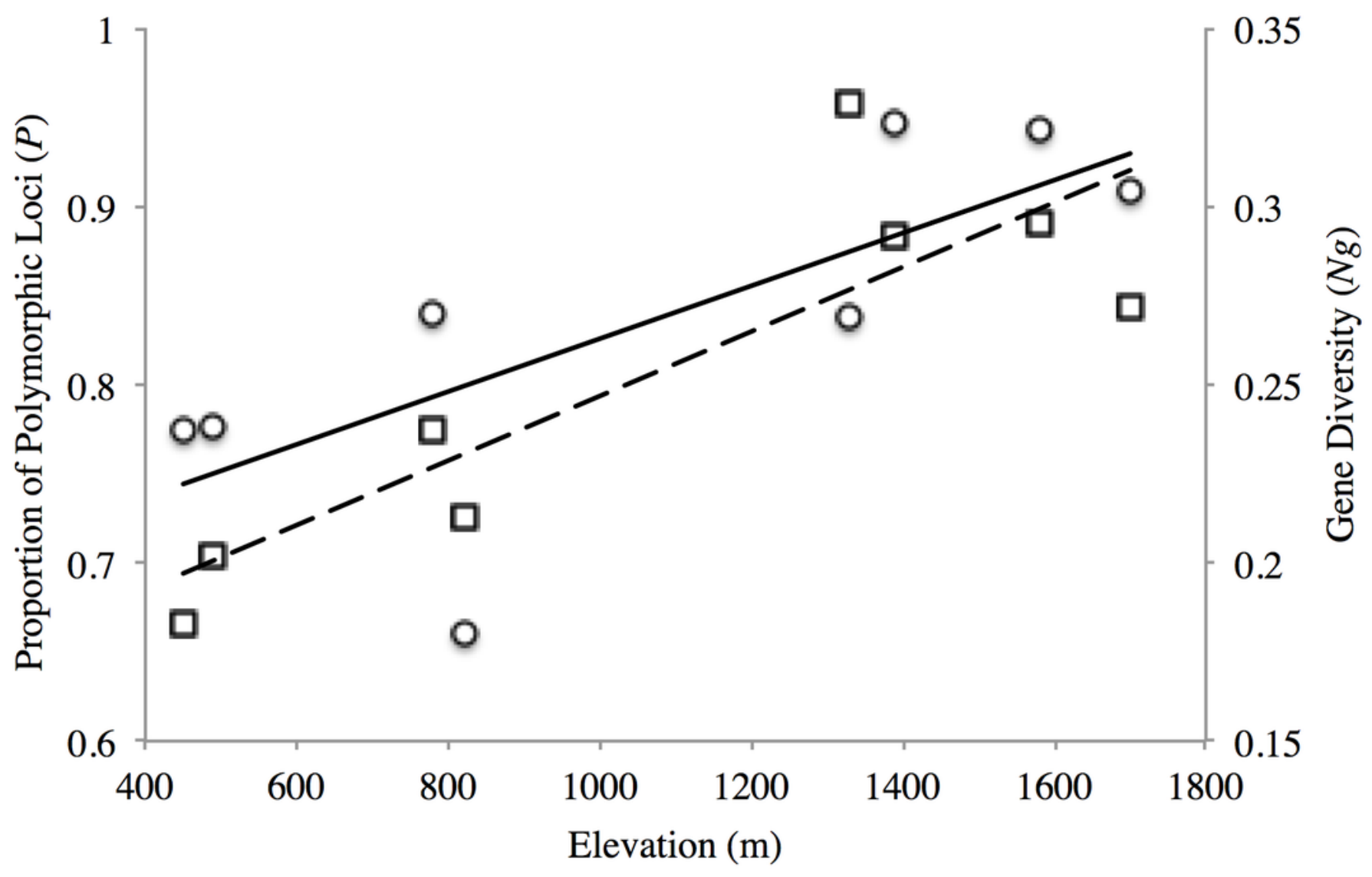


Table $\mathbf{1}$ (on next page)

Summary of outlier loci detected for American pika sampling sites along the Pyramid Peak (PP) and Thornton Lake (TL) elevational transects in North Cascades National Park. 
2 Table 1. Summary of outlier loci detected for American pika sampling sites along the Pyramid

3 Peak (PP) and Thornton Lake (TL) elevational transects in North Cascades National Park.

\begin{tabular}{|c|c|c|c|c|c|}
\hline Locus & SNP & Transect & $F_{\mathrm{ST}}{ }^{*}$ & $\begin{array}{l}\text { Top Blast hit } \\
\text { (Accession) }\end{array}$ & Abbreviated description \\
\hline 21404_70 & $\mathrm{C} / \mathrm{T}$ & $\mathrm{PP}$ & 0.315 & AC234826 & $\begin{array}{l}\text { Ochotona princeps clone } \\
\text { VMRC } 40-45 \mathrm{~K} 5\end{array}$ \\
\hline 33398_46 & $\mathrm{C} / \mathrm{T}$ & $\mathrm{PP}$ & 0.261 & XM004593395 & $\begin{array}{l}\text { Ochotona princeps thioredoxin-related } \\
\text { transmembrane protein } 4\end{array}$ \\
\hline $57863 \_76$ & $\mathrm{~A} / \mathrm{G}$ & $\mathrm{PP}$ & 0.255 & NG008089.1 & $\begin{array}{l}\text { Homo sapiens receptor tyrosine kinase- } \\
\text { like orphan receptor } 2\end{array}$ \\
\hline $23902 \_347$ & $\mathrm{C} / \mathrm{T}$ & $\mathrm{TL}$ & 0.248 & AC237024 & $\begin{array}{l}\text { Ochotona princeps clone } \\
\text { VMRC } 40-172 \mathrm{G} 4\end{array}$ \\
\hline $46878 \_140$ & $\mathrm{C} / \mathrm{G}$ & $\mathrm{TL}$ & 0.234 & AC234901 & Oryctolagus cuniculus, clone 0087B06 \\
\hline 72966_67 & $\mathrm{A} / \mathrm{G}$ & $\mathrm{PP}$ & 0.229 & AL358859 & $\begin{array}{l}\text { Human DNA sequence from clone } \\
\text { RP11-545G13 on chromosome } 1\end{array}$ \\
\hline $59691 \_160$ & $\mathrm{C} / \mathrm{T}$ & $\mathrm{TL}$ & 0.223 & AC234021 & $\begin{array}{l}\text { Ochotona princeps clone } \\
\text { VMRC } 40-93 \text { N24 }\end{array}$ \\
\hline 23486_75 & $\mathrm{A} / \mathrm{C}$ & $\mathrm{TL}$ & 0.209 & XM004585173 & Ochotona princeps hephaestin-like 1 \\
\hline 110148_49 & $\mathrm{A} / \mathrm{G}$ & $\mathrm{TL}$ & 0.196 & AC165118 & $\begin{array}{l}\text { Oryctolagus cuniculus, clone } \\
16788057 \mathrm{~J} 9\end{array}$ \\
\hline 94981_43 & $\mathrm{A} / \mathrm{T}$ & $\mathrm{PP}$ & 0.194 & AC236101 & $\begin{array}{l}\text { Ochotona princeps clone VMRC40- } \\
347 \mathrm{~J} 6\end{array}$ \\
\hline 43241_27 & $\mathrm{C} / \mathrm{T}$ & $\mathrm{TL}$ & 0.171 & AC233835 & $\begin{array}{l}\text { Ochotona princeps clone VMRC40- } \\
526 \mathrm{O} 13\end{array}$ \\
\hline 108547_114 & $\mathrm{A} / \mathrm{T}$ & TL & 0.165 & XM004587540 & $\begin{array}{l}\text { Ochotona princeps platelet-derived } \\
\text { growth factor receptor, beta }\end{array}$ \\
\hline 87086_98 & $\mathrm{C} / \mathrm{G}$ & TL & 0.155 & XM004593191 & $\begin{array}{l}\text { Ochotona princeps putative } \\
\text { uncharacterized protein FLJ46204-like }\end{array}$ \\
\hline 28594_45 & $\mathrm{C} / \mathrm{T}$ & $\mathrm{TL}$ & 0.153 & NG007853 & Homo sapiens laminin, alpha 3 \\
\hline
\end{tabular}

$4 \quad{ }^{*} F_{S T}$ values significantly higher than under neutral expectations; averaged over populations. 
Table 2 (on next page)

Genetic variation within American pika samples sites along the Pyramid Peak (PP) and Thornton Lake (TL) elevational transects in North Cascades National Park. 
2 Table 2. Genetic variation within American pika samples sites along the Pyramid Peak (PP) and

3 Thornton Lake (TL) elevational transects in North Cascades National Park.

\begin{tabular}{llllllll}
\hline Site & Elevation & $n$ & $P$ & $H_{o}$ & $H_{e}$ & $N_{g}$ & $F_{i s}$ \\
\hline PP1 & 450 & 8 & 0.774 & $0.282^{*}$ & 0.372 & 0.183 & $0.260^{*}$ \\
PP2 & 820 & 5 & 0.661 & $0.314^{*}$ & 0.425 & 0.213 & $0.295^{*}$ \\
PP3 & 1330 & 5 & 0.837 & 0.403 & 0.403 & 0.329 & 0.001 \\
PP4 & 1580 & 11 & 0.943 & 0.383 & 0.359 & 0.295 & -0.071 \\
TL1 & 490 & 6 & 0.777 & $0.368^{*}$ & 0.400 & 0.202 & $0.088^{*}$ \\
TL2 & 780 & 10 & 0.839 & $0.339^{*}$ & 0.362 & 0.237 & $0.067^{*}$ \\
TL3 & 1390 & 13 & 0.947 & 0.336 & 0.349 & 0.292 & $0.039^{*}$ \\
TL4 & 1700 & 9 & 0.908 & 0.356 & 0.364 & 0.272 & $0.023^{*}$ \\
\hline
\end{tabular}

4 Elevation in meters; sample size $(n)$; proportion of polymorphic loci $(P)$; observed

5 heterozygosity $\left(H_{o}\right)$; unbiased expected heterozygosity $\left(H_{e}\right)$; gene diversity $\left(N_{g}\right)$; inbreeding

6 coefficient $\left(F_{i s}\right) ; * p<0.05$.

7

8

9

10

11 


\section{Table 3(on next page)}

Pairwise $\theta$ estimates for American pika sites within and among the Pyramid Peak (PP) and Thornton Lake (TL) elevational transects in North Cascades National Park. 
2 Table 3. Pairwise $\theta$ estimates for American pika sites within and among the Pyramid Peak (PP)

3 and Thornton Lake (TL) elevational transects in North Cascades National Park.

\begin{tabular}{|c|c|c|c|c|c|c|c|c|}
\hline Site & PP1 & PP2 & PP3 & PP4 & TL1 & TL2 & TL3 & TL4 \\
\hline PP1 & - & 0.066 & 0.056 & 0.054 & 0.105 & 0.109 & 0.101 & 0.098 \\
\hline PP2 & & - & 0.040 & 0.049 & 0.096 & 0.101 & 0.087 & 0.088 \\
\hline PP3 & & & - & 0.020 & 0.072 & 0.072 & 0.062 & 0.056 \\
\hline PP4 & & & & - & 0.065 & 0.068 & 0.059 & 0.053 \\
\hline TL1 & & & & & - & 0.051 & 0.040 & 0.042 \\
\hline TL2 & & & & & & - & 0.027 & 0.030 \\
\hline TL3 & & & & & & & - & 0.015 \\
\hline TL4 & & & & & & & & - \\
\hline
\end{tabular}

4 Results based on 3,748 neutral single nucleotide polymorphisms. All pairwise $\theta$

5 estimates were significant $(\mathrm{p}<0.05)$. Pairwise values for among transect comparisons

6 shaded in gray.

7

8

9

10 


\section{3}

Figure 3: Structure bar plots depicting the model-based clustering results for Thornton Lake (TL) and Pyramid Peak (PP) sites based on outlier loci (above) and neutral loci (below).

Analyses for the TL transect revealed evidence for both $K=2(\Delta K=473.3)$ and $K=3(\Delta K=$ 314.6; plot shown) based on 37 outlier loci, and $K=1$ ( $K=2$ plot shown for display purposes) based on 3748 neutral loci. Analyses for the PP transect revealed evidence for $K=2$ ( $\Delta K=$ 123.1) based on 18 outlier loci, and $K=2(\Delta K=33.1)$ based on 3,748 neutral loci.

\section{Outlier}
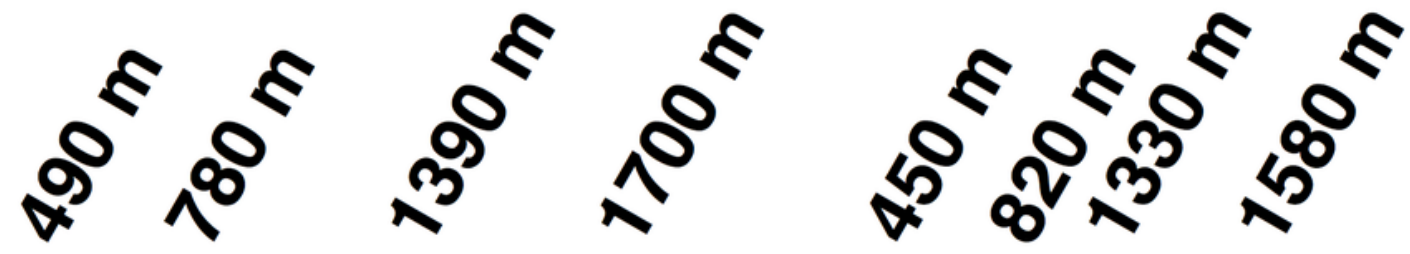

\section{Neutral}
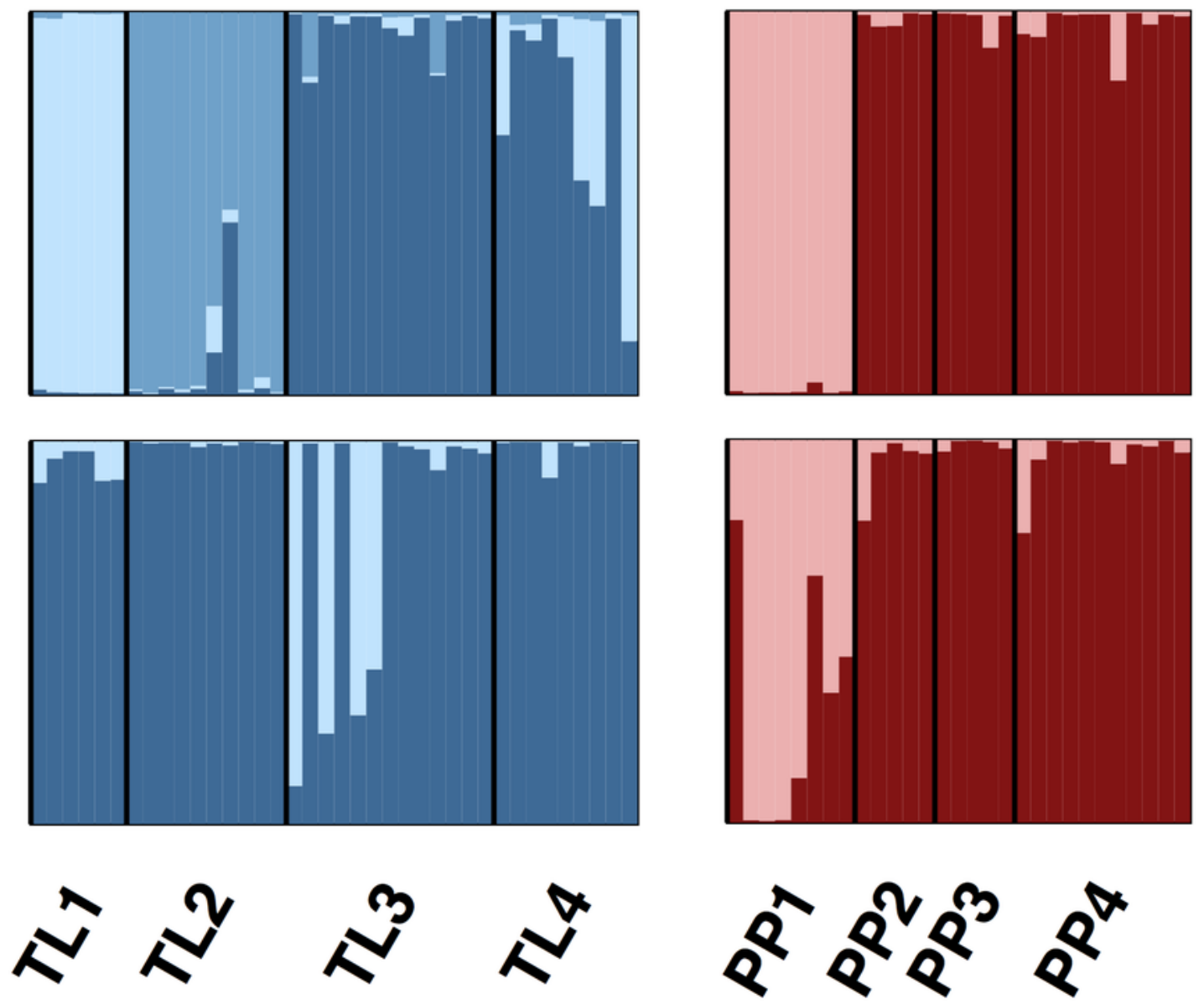